\title{
Service Orientation in Transitional Economies: Analysis of Critical Service Factors in two Slowenian Banks Compared to the USA*
}

\author{
Samo Bobek, Monty L. Lynn, Richard S. Lytle
}

Service quality, and the service-oriented practices that create that quality, have been shown to yield competitive advantage to firms in developed and mature markets. The role that service-driven practices play in transitional economies, however, has not been tested. In this study, the SERVOR scale, a measure of organizational service-orientation, was analyzed from 105 employees in two Slovenian banks-one which is a newly established private bank and the other which is a large, older previous state-supported bank. Results indicate that the private bank is more service-oriented in its approach to the marketplace.

Es hat sich erwiesen, daß Dienstleistungsqualität und dienstleistungsorientierte Verfahrensweisen, welche diese Qualität hervorbringen, Wettbewerbsvorteile für Firmen in entwickelten und etablierten Märkten bedeuten. Die Rolle, die dienstleistungsorientierte Praktiken in Wirtschaftssystemen spielen, welche sich im Transformationsprozeß befinden, wurde jedoch noch nicht untersucht. In der vorliegenden Studie wurde der SERVOR-Maßstab, ein Instrument zur Messung der Dienstleistungsorientierung einer Organisation, von 105 Angestellten in zwei slowenischen Banken analysiert. Eine der Banken ist eine neu gegründete private Bank, die andere eine große, ältere, früher staatlich unterstützte Bank. Die Ergebnisse zeigen, daß die private Bank einem stärker dienstleistungsorientierten Ansatz folgt.

\footnotetext{
* Manuskript received: 05.12.97 revised: 29.04 .98 accepted: 02.06 .98

** Samo Bobek, Vice Dean for Research and Professor of Information Systems, School of Business and Economics, University of Maribor, Slovenia; research interests: information systems in banking, business process re-engineering, management information systems, information systems management. Monty L. Lynn, Director of the MBA Program and Professor of Management, College of Business Administration, Abilene Christian University, Texas, USA; research interests: service quality, organizational service orientation, customer satisfaction, health care marketing. Richard S. Lytle, Associate Dean and Associate Professor of Marketing, College of Business Administration, Abilene Christian University, Texas, USA; research interests: organizational buffering, small firm diversification, health care administration, belief bias.
} 


\section{Introduction}

Service quality, and the service-oriented practices that create that quality, have been shown to yield competitive advantage to firms in mature Western markets (Jones \& Sasser 1995; Lytle, Hom, \& Mokwa, 1997). One industry in which service has been shown to offer competitive advantage--both in North America (Schneider \& Bowen 1995) and in Western Europe (Nader, Buhler \& Johnson, 1996; Schmid, 1996)--is banking. In mature markets where technology, accessibility, products, and security are roughly equivalent, innovative service can contribute to breakaway growth (Stalk, Pecaut \& Burnett, 1996).

The role that service-driven practices play in transitional economies, however, has not been tested.

In an effort to better understand customer service perceptions and practices we have used the Servor Scale (Lytle, Hom and Mokwa, 1997). Although this instrument has been used in many types of organizations, it has been used most extensively in banks in the United States. Data now exists from surveys of hundreds of employees in several small and large American banks. These surveys have provided information on banking services and have allowed the scale to be proven as a valid and reliable measure of customer service perceptions and practices.

The purpose of this study was to take the Servor scale across US borders and into an international setting. The setting of choice was Slovenia. In this study, the SERVOR scale, a measure of organizational service-orientation (Lytle, Hom, \& Mokwa, 1997), was analyzed from 105 employees in two Slovenian banks-one which is a newly established private bank and the other which is a large, older state-supported bank. Bank performance ultimately is not measured by comparing Slovene and US banks, but in gauging how each of Slovenian banks performs relative to other banks in Slovenia. Employees in a bank are comparing their bank's performance with regional banks, not with American banks. Though American bank data is provided, it is provided as a simple contrast to the Slovenian banks data.

\section{Literature Review}

Service and service quality are central issues in the marketplace today. Throughout the decade, scholars and executives have continually ranked improving service quality as one of the most critical challenges facing business (Albrecht and Zemke 1985; Heskett, Sasser, and Hart 1990; Roach 1991; Schlesinger and Heskett 1991; Sewell and Brown 1992; Zeithaml, Parasuraman, and Berry 1990). The importance of service is not restricted to a few organizations and industry settings. In fact, the significance of service is quite 
broad-based. "Virtually all organizations compete to some degree on the basis of service. It is difficult to name even one industry for which service matters are unimportant...As executives find it increasingly difficult to establish sustainable, technology-based competitive advantages, they will direct added attention and resources to value-added service as a truer source of superiority" (Zeithaml, Parasuraman, and Berry 1990, pp. 1-3).

Research affirms this view and suggests that customer satisfaction, customer loyalty, and organizational success are associated with an organization's service performance (Berry, Parasuraman, and Zeithaml 1994; Bitner 1992; Jones and Sasser 1995). Service performance is a function of several key organizational factors. First, strong and widespread management commitment to service quality must exist. It is this commitment that energizes and stimulates organizations to improved levels of service performance (Gibbs 1995; O'Connor and Shewchuk 1995; Schneider and Bowen 1995; Zeithaml, Parasuraman, and Berry 1990).

Second, strong and widespread employee commitment to service quality must exist. It is employee behavior oftentimes that directly shapes customer perceptions of service performance and thus customer satisfaction and loyalty (Bitner 1990, 1992; Jones and Sasser 1995). Traditional research supports the idea that customer evaluations of quality service (Parasuraman, Zeithaml, and Berry 1985) directly depend on service-oriented individuals existing at critical junctures in the organizational service creation and delivery chain (Bowen and Schneider 1988; Bowen, Siehl, and Schneider 1989). Determinants of service quality include dimensions such as empathy, caring, understanding, and reliability experienced by customers in the actual service encounter (Parasuraman, Zeithaml, and Berry 1988). In fact, more recent research focuses specifically on customer attitudes and feelings created during the actual employee/customer service encounter. This work finds that customer service perceptions are, partly, a function of service providers' attitudes and actions (Bitner 1990, 1992, 1995).

Third, an organizational service-orientation must exist creating a climate for sustainable, long-term service performance and the creation of superior value. The relationship between an organization's orientation and employee behavior is critical: Employee behavior is a function of an organization's orientation (Bowen and Schneider 1988; Schneider and Reichers 1990; Schneider, Wheeler, and Cox 1992). Service-oriented organizations will establish and embrace relatively enduring policies, practices, and procedures that support and reward excellent employee service behavior. It is purported that these organizations are more likely to deliver outstanding service performance resulting in higher levels of customer satisfaction, customer loyalty, and organizational success. Without an organizational service-orientation, the likelihood of sustainable, long-term service performance is diminished. 
Though numerous articles and management groups advocate service excellence and the importance of nurturing an organizational service-orientation, few studies have focused on the systematic development of parsimonious and psychometrically sound empirical measurement models (Berry, Conant, and Parasuraman 1991; Dabholkar, Thorpe, and Rentz 1996; Schneider, Wheeler, and Cox 1992). As such, there is a need for clear specification and measurement of the organizational practices and routines that determine excellent service and comprise an organizational service orientation (OSO). Furthermore, there is a critical need for measures to be managerially relevant: simple yet elegant. Many measurement models are unnecessarily complex and arduous. Useful organizational measures should be reliable and valid, but also simple and effective tools for managers to use as they attempt to assess and manage their organization's service-orientation.

\section{Methodology}

In the survey the Servor Scale was used as a research model (Lytle,Hom and Mokwa, 1997). The Servor Scale is comprised of 9 separate dimensions that are intended to measure critical organizational "best practices" necessary for creating and delivering outstanding service quality. The Servor Scale dimensions are:

- customer treatment,

- employee empowerment,

- servant leadership,

- service training,

- service rewards,

- service failure prevention,

- service failure recovery,

- service technology,

- service standards communication.

The dimensions are operationalized or measured by asking employees to respond to different similar but distinct questions for each dimension. The questionaire consist of 34 questions. Interpretation of the responses is based on the scale ranged from 7 to 1 where the distinct scores have the following meaning:

- $7=$ Strongly agree

- $6=$ Agree

- $5=$ Somewhat agree 
$4=$ Neutral

$3=$ Somewhat disagree

$2=$ Disagree

$1=$ Strongly disagree.

The Servor Scale was for the purpose of its usage in Slovenia translated into Slovene and then reverse translated into English to identify any problematic linguistic or cross-cultural phrases.

Respondents in this study were employees of two banks in Slovenia, noted here as StateBank and PrivateBank. StateBank is an old bank. PrivateBank was established in 1991. Although originally funded by a small number of private investors, shares of PrivateBank are now traded on the Slovene stock market. StateBank has about three times the assets of PrivateBank. Due to their differences in capitalization, age, and size, we conclude that PrivateBank is more exposed to competitive market pressures than is StateBank.

Employees participating in the survey identified the branch or office in which they work and indicated whether or not they are a manager. This level of identification was requested so that manager and non-manager perceptions could be compared, and so branch and office perceptions could be compared as well (without linking the identity of any particular branch or office with the responses gathered). The identity of individual respondents remained anonymous to encourage honest employee responses.

Questionnaires were distributed to 263 front-and back-office employees of StateBank. A total of 75 useable questionnaires were returned, yielding a response rate of $28.5 \%$. Represented in the data were 5 corporate departments and 6 branches. Within the offices/branches which responded, the response rate was $64.7 \%$. $12 \%$ of the sample respondents were male and $88 \%$ of the sample respondents were female. For the bank, this appears to be a fair representation of "back-office" employees by gender. 93\% of sample respondents classified themselves as regular employees versus $7 \%$ of employees who classified themselves as holding managerial positions.

In PrivateBank 33 questionnaires were distributed to 33 front- and back-office employees in two corporate departments and one branch. A total of 30 usable questionnaires were returned, yielding a response rate of $91 \%$. The majority of respondents were female (23\%); most (64\%) did not hold management position.

An overall response rate was $35 \%$. StateBank employees represent roughly twothirds of the sample. The majority of the respondents were female, nonmanagerial employees. 


\section{Some Comments on Interpreting the Results}

Many of the Servor questions ask the respondent to compare practices at his/her bank with practices at one or more competing banks. Though American bank data is provided, it is provided as a simple contrast in the Slovenian bank data. It is important to note that:

Bank performance ultimately is not measured by comparing Slovene and US banks, but in gauging how Slovenian bank performs relative to other banks in Slovenia. Employees in a bank are comparing their bank's performance with regional banks, not with American banks.

Occasionally, interpretation is offered relative to the US bank data, but the focus clearly should be on the perceptions of employees at Slovenian bank.

When interpreting data in this study, it is important to keep four broad considerations in mind:

How do customers define service quality in Slovene banking?

How wide is the gap between what customers expect and what the bank actually delivers?

What resources do employees need to provide exceptional customer service? Are those resources available?

Do the methods used to collect data in this study give an accurate reading of employee perceptions?

Each of these considerations will be addressed briefly.

Customers define service differently across different companies, industries, cultures, and times. The qualities which many Slovenians expect from their banks may include financial security, the availability of particular banking services, how long they have to wait, personal attention, exchange rates, modern facilities, evening hours, or competent bank employees. Customers may value some of these factors more than others. And they may change what they value as technology evolves and as competition among banks escalates. By the same token, when a bank provides a service which is not desired by customers, its service is not enhanced. Even as a moving target, it helps to know what customers want from their bank.

The next step in thinking about service quality is identifying how large a gap exists between what customers desire in terms of service and what the bank actually delivers. If a customer's expectations of bank service is fairly low--if he expects long lines, little personal attention, and slow processing, for example-then what overall might look like a poorly functioning bank might not be defined that way by the customer. But as customers experience higher levels of service in banks and other types of organizations, the service gap may widen. Customer service often takes on increasing importance as bank competition 
rises. Increases in the number of providers of banking services may cause a relatively steep increase in the demand that customers make for responsive service.

What resources do employees need to provide exceptional customer service. Rewards? Training? Incentives? The example of leadership? Communication technology? Empowerment? Are those resources available? It may not be that customer service standards are unknown to employees, or that they don't understand what it would take to deliver better service. It may be that the organization doesn't provide a setting which supports enhancements in service delivery. Management often sets the tone in service. If management is not service oriented, efforts in the bank to encourage responsive customer service may create little improvement. Thus, broad thinking needs to be given internally to aspects of the organization which support what it takes to deliver high quality service.

Research data are only as good as the methods used to collect them. Thus, one should consider possible methodological influences may have affected the outcomes. Particularly since employee opinions were measured cross-culturally, careful attention needs to be given to potential cultural biases in the data gathering.

Some translated survey items, for instance, may create different mental images across cultures. Additionally, employees who are unaccustomed to anonymous survey methods may feel uncomfortable giving their real opinions. If employees think they may be punished for their responses, they may give the responses which management wants to hear. Further, employees may not give accurate comparisons of bank practices if they are unfamiliar with any other banks.

Thus, to appropriately interpret the data, one must carefully consider the possible influences these factors may have in the thinking and reaction of Slovenian bank employees and customers.

\section{Results}

\subsection{Customer Treatment}

The meaning, definition, and evaluation of service quality exists entirely in the mind of the customer (Chase and Bowen 1991; Parasuraman, Zeithaml, and Berry 1988). Organizations that consistently engage in practices enacting the "golden rule" during service encounters create positive customer perceptions of service performance (Bitner, Booms, and Tetreault 1990; Bitner 1990; Parasuraman, Zeithaml, and Berry 1988). It is the physical treatment of the customer that creates strong impressions of service quality in the customer's mind. 
This dimension seeks to assess employee perceptions of how they believe their unit takes care of its customers. The dimension is operationalized or measured by asking employees to respond to four similar but distinct questions. The average scores:

Question "Employees care for their customers as they would like to be cared for" are 5 in StateBank and 5,23 in PrivateBank (5,1 in US).

Question "Employees go second mile for customers" are 4,95 in StateBank and 5,19 in PrivateBank (5,15 in US).

Question "We are noticeably more friendly and courteous than our competitors" are 5,49 in StateBank and 5,13 in PrivateBank (5,44 in US).

Question "Employees go out of their way to reduce inconveniences for customers" are 5,51 in StateBank and 5,55 in PrivateBank (5,26 in US).

In StateBank employees somewhat or moderately agree that customers are being taken care of in their respective units. There is not a significant difference in responses between employees of US Banks and employees of StateBank. However, the findings suggest that employees believe that much more could be done to give customers the type of treatment they desire and deserve.

In PrivateBank employees agree that customers are well served and that extra efforts are taken to serve the customer. In three of four cases, the PrivateBank employees evaluated their service higher than did the average employee in a US bank. But recall that the US employees are comparing their service to competing US banks while PrivateBank employees are comparing their service to competing banks in Slovenia.

\subsection{Employee Empowerment}

Since service production and consumption occurs simultaneously (Bateson 1989; Bitner, Booms, and Tetreault 1990; Parasuraman, Zeithaml, and Berry 1985), employees must have responsibility and authority that allows them to tailor service production as service complications and/or service opportunities arise. Organizational members who have the directive, responsibility, and authority to provide superior customer service have been empowered by management and are more able to provide high levels of quality service ( Heskett 1987). Empowered employees can make important decisions "close to the customer." In other words, employees can make decisions "on the spot" instead of having to obtain management permission "up the ladder."

This dimension seeks to assess employee perceptions of how empowered they feel. The more empowered they feel, the more likely they are to be involved in the types of behavior that will produce high levels of customer satisfaction. The dimension is operationalized or measured by asking employees to respond to two questions. The average scores for: 
Question "Employees often make important customer decisions without seeking management approval" are 3,24 in StateBank and 4,06 in PrivateBank (3,76 in US).

Question "Employees has freedom and authority to act independently in order to provide excellent service" are 3,35 in Statebank and 4,26 in PrivateBank (3,91 in US).

In StateBank employees do not feel empowered to autonomously take care of customer needs. US bank employees seem to feel somewhat more empowered than Slovene bank employees. The findings suggest that management might consider the appropriateness of providing more empowerment within the bank's organizational culture.

In PrivateBank employees are neutral regarding whether they are empowered to take care of customer needs without obtaining management's approval. Still, PrivateBank employees perceive themselves as being more empowered than do average US bank employees.

\subsection{Servant Leadership}

This construct concerns management's leadership style. "Servant-leaders" actually "walk the service talk." They direct and manage their organizations by setting conspicuous service examples rather than simply dictating service policy for the organization (Albrecht and Zemke 1985; 1990; Heskett 1986; Schlesinger and Heskett 1991). Thus, servant-leaders motivate the entire workforce, especially front-line employees, by setting service examples to be followed which reinforces higher service activity by all employees.

This dimension seeks to assess employee perceptions of how servant-driven their managers are. The more servant-oriented managers are, the more likely employees will be servant oriented as they deal with customers. The dimension is operationalized or measured by asking employees to respond to six similar but distinct questions. The average scores for:

Question "Management constantly communicates the importance of service" are 3,62 in StateBank and 5,1 in PrivateBank (5,41 in US).

Question " Management regularly spent time with customers and front-line employees" are 2,91 in StateBank and 4,32 in PrivateBank (4,8 in US).

Question "Management is constantly measuring service quality" are 3,32 in StateBank and 4,39 in PrivateBank (4,92 in US).

Question "Management shows that they care about service by constantly giving themselves" are 3,09 in StateBank and 4,61 in PrivateBank (4,89 in US).

Question "Management provides resources, not just lip service to enhance employee ability to provide excellent service" are 3,26 in StateBank and 4,77 
in PrivateBank (4,7 in US).

Question "Managers give personal input and leadership into creating quality service" are 3,36 in StateBank and 4,77 in PrivateBank (4,95 in US).

Employees in StateBank do not feel that their managers exhibit high levels of servant leadership. The average score for these questions was low. They ranged from 2.91 to 3.62. Thus, on average, few employees perceived that managers exhibited core characteristics of servant leadership.

PrivateBank employees are neutral to somewhat agree that that their managers exhibit high levels of servant leadership. Cross-cultural note: Although servant leadership has been found to correlate with service practices in US banks, business leadership styles vary dramatically from culture to culture.

\subsection{Service Training}

Successful service encounters are significantly impacted by employee training (Chase and Bowen 1991; Schlesinger and Heskett 1991). According to Schlesinger and Heskett (1991), successful service organizations value investment in people as much as investment in machines and view technology as a means for supporting the efforts of workers instead of replacing them. Without proper service training, the ability of employees to meet the complex service demands of customers may be hindered.

This dimension seeks to assess employee perceptions of how much service training exists in their organizational culture. As more service training occurs within the culture, the likelihood of successful service delivery increases. The dimension is operationalized or measured by asking employees to respond to four similar but distinct questions. The average scores for:

Question "Every employee receives personal skills training which enhances his/her ability to deliver high quality service" are 3,71 in StateBank and 4,9 in PrivateBank (4,31 in US).

Question "We are taught, coached, and trained how to work effectively as a team" are 4,09 in StateBank and 4,61 in PrivateBank (4,24 in US).

Question "We spend much time and effort in simulated training activities that help us to provide higher levels of service when actually encountering the customer" are 4,58 in StateBank and 4,8 in PrivateBank (3,74 in US).

Question "During training sessions we work through exercises to identify and improve attitudes toward service and customers" are 3,94 in StateBank and 4,23 in PrivateBank (4,13 in US).

Statebank employees do not feel that they receive a great degree of service skills training. Scores ranged from 3.71 to 4.58 indicating that, on average, employees do not agree with statements that suggest they receive a fair amount of service skills training. 
PrivateBank employees mildly agree that they receive a great degree of service skills training. Scores ranged from 4.23 to 4.9 indicating that, they receive some skills training but that there is light emphasis on working as a customer-service team or on influencing attitudes toward customers.

\subsection{Service Rewards}

Many scholars and writers agree that an important element of service quality is the link between compensation and service performance (Heskett, Sasser, and Hart 1990; Roach 1991; Schlesinger and Heskett 1991). Service-driven organizations recognize and reward service accomplishments conspicuously within the organizational environment.

This dimension seeks to assess employee perceptions of "if and how" excellent service behavior is rewarded within their organizational culture. The dimension is operationalized or measured by asking employees to respond to two questions. The average scores for:

Question "Management provides excellent incentives and rewards at all levels for service quality, not just productivity" are 3,07 in StateBank and 3,97 in Privatebank (3,9 in US).

Question "This organization noticeably celebrates excellent service" are 2,64 in StateBank and 3,45 in PrivateBank (4,44 in US).

StateBank employees do not feel that service excellence is rewarded within their particular work culture. Scores ranged from 2.64 to 3.07 indicating that, on average, employees do not agree with statements that suggest they receive rewards for excellent service performance. It should be understood while interpreting this data that, on average, most employees disagree with statements that suggest they are rewarded for great service.

PrivateBank employees evaluated this dimension lower than any other, suggesting that the reward structure does not significantly support customeroriented service practices. Responses were 3.45 and 3.97 indicating slightly negative responses toward an application of incentives or the celebration of excellent service.

\subsection{Service Failure Prevention}

Researchers are increasingly attending to the design and operation of service delivery systems (Chase and Bowen 1991; Heskett, Sasser, and Hart 1990; Lovelock 1988; Schlesinger and Heskett 1991). Recent works have stressed that the creation and delivery of service quality requires an organized, systematic, and system-wide effort. Because service encounters are an important source of information for consumers in evaluating service quality, controlling and enhancing the service encounter through preventative service design is a critical task for organizations (Chase and Bowen 1991). 
This dimension seeks to assess employee perceptions of "if and how" excellent service behavior is designed into their organizational culture. Specifically, this dimension seeks to assess the extent to which the bank is seeking to prevent service failure by designing preventative systems ahead of time. The dimension is operationalized or measured by asking employees to respond to three similar but distinct questions. The average scores for:

Question "We go out of our way to respond to customer problems" are 5,47 in StateBank and 5,58 in PrivateBank (5,18 in US).

Question "We go out of our way to prevent customer problems rather than reacting to problems once they occur" are 5,71 in StateBank and 5,84 in PrivateBank (4,93 in US).

Question "We actively listen to customers " are 5,9 in Statebank and 5,74 in PrivateBank (5,4 in US).

StateBank employees do feel that customer service problems are responded to by bank personnel. It might be noted here that the phrase "actively listening to customers" might not have as strong a meaning in Slovenia as in the US. Generally speaking, "actively listening to customers" means conducting market research, collecting customer opinions, going to extraordinary lengths to hear what the bank's customers have to say.

Employees gave PrivateBank its highest evaluation on this dimension (5.58 to 5.84). Employees generally agree that bank personnel respond to customer service problems. PrivateBank's evaluation was strongly positive on service failure prevention.

\subsection{Service Failure Recovery}

At the other end of the spectrum from service prevention are issues of service failure and recovery. Berry, Parasuraman, and Zeithaml (1994) suggest that service failure recovery is an important determinant of service quality. They argue that if an organization fails to resolve customer problems, they have in fact disappointed the customer twice: once for the initial failure and twice for failing to correct what had gone wrong in the first place. Some research suggests that immediate and planned responsiveness to service failure can enable an organization to retain up to $95 \%$ of its dissatisfied customers (Albrecht and Zemke 1985).

This dimension seeks to assess employee perceptions of the organization's attempt to plan strategies to be engaged when service failure recovery occurs. The dimension is operationalized or measured by asking employees to respond to three similar but distinct questions. The average scores for:

Question "We have an excellent customer complaint handling system for service follow-up" are 3,87 in StateBank and 4,65 in PrivateBank (4,01 in 
US).

Question "We have established problem-solving groups to enhance our ability to resolve service breakdowns" are 3,29 in StateBank and 3,67 in PrivateBank (3,54 in US).

Question " Every employee knows what determines a good and bad service experience" are 4,47 in StateBank and 4,71 in PrivateBank (4,92 in US).

Employees in StateBank do not feel that the bank engages in service failure recovery behavior. "Best practices" such as service guarantees, follow-up service calls, and employee problem solving groups, in general, do not exist in the bank's organizational culture which is reflected in its daily practices. The scores in this category were well below a 4.00 - meaning that, on average, no one agreed that StateBank had active service failure recovery strategies.

Employees mildly agree that PrivateBank guarantees service, and has a process for handling customer complaints. But they do not do this in problem-solving groups or teams, nor do they follow-up with customers through service calls. Cultural differences are likely evident here between US and Slovene banking practices. Additionally, a "service guarantee" may be interpreted differently in the two countries.

\subsection{Service Technology}

Technological superiority is suggested to be one critical dimension utilized by successful firms today as they compete to deliver superior customer value (Treacy and Wiersema 1993). These systems are providing competitive advantage and assisting firms in the creation and production of service quality. This particular dimension focuses on the degree to which the organization is perceived by its employees as leveraging technology to provide a service advantage for the customer.

This dimension seeks to assess employee perceptions of the organization's attempt to use new technologies to create and deliver outstanding service value to customers. The dimension is operationalized or measured by asking employees to respond to three questions. The average scores for:

Question "We enhance our service capabilities through the use of "state of the art" technology" are 3,09 in StateBank and 5,16 in Privatebank (5,23 in US).

Question " Technology is used to build and develop higher levels of service quality" are 3,71 in StateBank and 5,26 in PrivateBank (3,58 in US).

Question "We use high levels of technology to support the efforts of men and women on the front- line" are 3,62 in StateBank and 5,16 in PrivateBank $(3,31$ in US). 
StateBank employees do not feel that the bank does a good job of utilizing "cutting edge" technologies to provide customers with outstanding levels of added value through service. As was the case in the last category, the scores in this category were well below a 4.00 - meaning that, on average, no one agreed that StateBank was using new technologies to support employees and deliver high levels of service through technology.

PrivateBank employees evaluated this dimension very highly. They clearly agree that PrivateBank's technology is state-of-the-art, and that that technology enables them to provide high quality customer service.

\subsection{Service Standards Communication}

Service measurement and standards must exist if service quality is to exist (Chase and Bowen 1991; 1990; Heskett 1986). Based on preliminary focus group research, high levels of service quality are attained by those organizations that measure, control, and communicate service quality standards and information across the organization.

This dimension seeks to assess employee perceptions of the organization's ability to communicate what is expected from all employees in terms of service standards, practices, and behaviors. The dimension is operationalized or measured by asking employees to respond to five similar but distinct questions. The average scores for:

Question "We do not wait for customers to complain, we use internal standards to pinpoint failures before we receive customer complaints" are 3,41 in StateBank and 4,65 in PrivateBank (4,01 in US).

Question "Every effort is made to explain the results of customer research to every employee in understandable terms" are 3,37 in StateBank and 3,67 in PrivateBank (4,04 in US).

Question "Every employee understands all of the service standards that have been instituted by all departments" are 3,17 in StateBank and 3,48 in PrivateBank (3,77 in US).

Question "We have a developed chain of objectives linking together every branch in support of the corporate vision" are 3,46 in StateBank and 4,5 in PrivateBank (3,92 in US).

Question "Service performance measures are communicated openly with all employees regardless of position or function" are 3,29 in Statebank and 4,71 in PrivateBank $(4,4$ in US).

Employees in StateBank do not feel that the bank does a good job of communicating its service standards throughout the organization. As was the case in the last two categories, the scores in this category were well below a 4.00 , meaning that, on average, no one agreed that StateBank was 
communicating its service strategies to everyone in the bank. Since the findings indicate that, for the most part, StateBank does not engage in overt service enhancement practices, it follows that these practices (which do not exist) are not communicated within and across the organization.

PrivateBank employees mildly agree that the bank does a good job of communicating its service standards throughout the organization. Employees are not very aware, however, of the service standards in various departments, nor do they have occasion to discuss customer research with customers.

\section{Discussion}

F-tests for equality of variances for each of the SERVOR dimensions indicated that the two bank samples were not significantly different in variance. Subsequently, independent sample t-tests were used to test for differences between the SERVOR dimensions at StateBank and PrivateBank. Two banks differed significantly on seven of the SERVOR dimensions. On each, PrivateBank was significantly higher $(<, 001)$ than StateBank.

In general, Statebank employees moderately agree that:

customers are being served adequately at present

customer service problems are responded to by bank personnel.

The findings suggest that employees believe that there is room for improvement, however, in StateBank advancing to provide exceptional customer service. In general, StateBank employees do not feel that:

- they are empowered to autonomously take care of customer needs

- their managers exhibit high levels of servant leadership

- they receive a great degree of service skills training

service excellence is rewarded within their particular work culture

the bank engages in service failure recovery behavior

the bank does a good job of utilizing "cutting edge" technologies to provide customers with outstanding levels of added value through service

the bank does a good job of communicating its service standards throughout the organization.

The results of this study clearly indicate that StateBank is not service-oriented organization in its approach to the marketplace. StateBank employees do not embrace a basic organization-wide set of relatively enduring organization policies, practices, and procedures intended to support and reward service-giving behaviors that create and deliver "service excellence".

In general, PrivateBank employees firmly agree that: 
- they are providing the level of service that customers want

- provide more friendly and curtious service than do other banks

- go out of their way to reduce inconveniences

- managers communicate service to employees

- employees go out of their way to head off and respond to customer problems

- employees actively listen to customer's concerns and desires

- their technology is state-of-the art, supports the front-office employees, and helps provide quality service

PrivateBank employees mildly agree or are neutral that:

- they are empowered and have freedom to make decisions on behalf of the customer

- managers give of themselves, provide resources, and personally lead

- service quality is measured

- employees are taught to work as a team and be customer-oriented

- employees know what constitutes high and low quality service

- a customer complain handling system operates and service guarantees are offered

- measures of service are communicated, branches are linked by common service objectives

- problems are pinpointed before customers complain

PrivateBank employees mildly disagree that:

- incentives for quality service exist

- excellent service is celebrated

- problem-solving is handled by employee teams or groups

- follow-up service calls are made

- employees describe customer research clearly to customers

- employees understand other departments' service standards

The results of this study clearly indicate that PrivateBank is a service-oriented organization in its approach to the marketplace. PrivateBank employees embrace a basic organization-wide set of relatively enduring organizational policies, practices, and procedures intended to support and reward service-giving behaviors that create and deliver "service excellence." The data support the notion that an association exists between competitive market pressure, organizational performance, and organizational service orientation. We conclude from this that PrivateBank is better positioned than StateBank--regardless of 
other financial and operational considerations--to compete as the Slovene economy becomes increasingly competitive.

In competitive market economies, customers are discriminating, have higher expectations, and have multiple products available to satisfy their needs and desires (Jones \& Sasser 1995). The result is that customers demand higher levels of service quality and make decisions based on an organization's ability to deliver it. In fiercely competitive markets, service quality is directly linked with customer satisfaction, loyalty, and organizational performance (Jones \& Sasser 1995). This research suggests that a similar relationship may exist in transitional economies.

\section{Conclusion}

The results of this study clearly indicate that PrivateBank is much more serviceoriented in its approach to the marketplace than StateBank. PrivateBank employees felt more empowered by management to respond to customer needs. They also witnessed higher levels of servant leadership among managers, meaning that managers set excellent service examples by personally serving employees and customers. PrivateBank personnel reported that their bank did a significantly better job of utilizing technology to create and deliver service excellence than did other banks. Through better communication practices, PrivateBank employees also perceived that they were better informed about what exactly was expected in terms of customer service practices. Additionally, service training practices were noticeably higher in PrivateBank than at StateBank.

Though a statistically significant difference existed between PrivateBank and StateBank in terms of service failure recovery practices, the overall means were quite low. This shows that employees at both banks perceive their employer to be engaged in comparatively little service failure prevention or service failure recovery planning. Additionally, though a statistically significant difference existed between the two banks in terms of service rewards, the means were extremely low indicating that neither organization does a good job of engaging in strategies that reward employees for outstanding customer service practices.

There were no significant differences in means between the two banks in: (1) customer treatment, (2) service vision, (3) service failure prevention. In terms of customer treatment, employees at both banks indicated that they do a good job of taking care of customer needs. Both banks' scores were relatively high. Both banks' scores indicate that their respective management teams fairly clearly articulate a service vision for the organization. Finally, employees at both banks indicated that they felt like their banks did a pretty good job of attempting to "head off" service failures before they occur. In light of other results, employees at both banks feel like they treat their customers well, but only PrivateBank 
employees actually engage in practices that would enhance its likelihood to do so.

As we stated earlier customers define service differently across companies, industries, cultures, and times. If a customer's expectations of bank service are fairly low--if he or she expects long lines, little personal attention, and slow processing, for example--then what looks like a poorly functioning bank might not be defined that way by the customer. Customer service often takes on increasing importance as bank competition escalates. Increases in the number of providers of banking services, especially as supply matches demand, may cause a relatively steep increase in customer expectations and in service improvement.

Providing additional services, products, or quality, will add to customer service only if the customer values those enhancements. Customers define what service is. Although banks may anticipate and even lead changes in these expectations, the customer perspective is paramount. Thus, to be service-oriented, banks need to monitor what customers want and identify where gaps exists between customer expectations and the bank's delivery of services and products. Banks which perceive, understand, and act on customer desires and expectations will more likely gain competitive advantage locally and be in a potentially better competitive position to expand in their home market.

The SERVOR instrument can assist management in measuring the service gap in several ways. First, the SERVOR scale can establish baselines of service performance for the entire organization as well as different units within the organization. Second, it can be used to systematically monitor and track the organization's performance on each of the ten dimensions. Finally, the results of each SERVOR administration can be used to (1) identify pockets of service excellence and provide appropriate praise and rewards, and (2) identify organizational service challenges/weaknesses in order to allocate appropriate training and resources to remedy the service problems that exist.

After identifying customer needs and service gaps, the bank must provide supports for service delivery enhancement. For example, if management is not service-oriented, efforts in the bank to encourage responsive customer service may create little improvement. Thus, broad thinking needs to be given to aspects of the bank's changing culture and organization which support or impede the delivery of high quality service. More detailed recommendations for developing service practices are readily available (e.g., Albrecht \& Zemke, 1985; Sewell \& Brown, 1992).

Replications and extensions of this study would enhanced the present result if they compared with another bank in Slovenia or more than two organizations or collected branch level performance data to allow statistical examination of service practices and performance. It will also be interested to test whether on organizational service orientation, operationalized in terms of daily service 
practices and procedures, is associated with market exposure and bank performance in transitional economy.

\section{References}

Albrecht, Karl / Ron Zemke (1985): Service America! Doing Business in the Service Economy, Homewood, IL: Dow Jones/Irwin.

Bateson, John E.G. (1989): Managing Services Marketing. Chicago: The Dryden Press.

Berry, Leonard L., A. Parasuraman /Valerie A. Zeithaml (1994): Improving Service Quality in America: Lessons Learned, in: Academy of Management Executive, 8 (2), pp 3252.

Bitner, Mary Jo (1990): Evaluating Service Encounters: The Effects of Physical Surrounding and Employee Responses, in: Journal of Marketing, 54 (April), pp 69-82.

Bitner, Mary Jo (1992): Servicescapes: The Impact of Physical Surroundings on Customers and Employees, in: Journal of Marketing, 56 (April), pp 57-71.

Bitner, Mary Jo, Bernard M. Booms / Mary Stanfield Tetreault (1990): The Service Encounter: Diagnosing Favorable and Unfavorable Incidents, in: Journal of Marketing, 54 (January), pp 71-84.

Bowen, David E. / Richard B. Chase/ Thomas G. Cummings / Associates (1990): Service Management Effectiveness: Balancing Strategy, Organization and Human Resources, Operations, and Marketing, San Francisco: Jossey-Bass Publishers.

Bowen, D.E. / Benjamin Schneider (1988): Services Marketing and Management: Implications for Organizational Behavior, in Barry M. Staw / L.L. Cummings (eds.), Research in Organizational Behavior, vol. 10. Greenwich, CT: JAI Press.

Bowen, D.E., C. Siehl / B. Schneider (1989): A Framework for Analyzing Customer Service Organizations in Manufacturing, in: Academy of Management Review, 14 (January), pp 75-95.

Chase, Richard B. / David E. Bowen (1991): Service Quality and the Service Delivery System: A Diagnostic Framework, in: Service Quality: Multidisciplinary and Multinational Perspectives. Cambridge, MA: Lexington Books.

Gibbs, Christine (1995): How to Make Customer Service Work?, Public Management, 77 (8), pp 14-29.

Heskett, James L. (1986): Managing in the Service Economy. Boston: Harvard Business School Press.

Heskett, James L. /W. Earl Sasser, Jr. / Christopher W.L. Hart (1990): Service Breakthroughs: Changing the Rules of the Game. New York: The Free Press.

Heskett, James L. (1987): Lessons in the Service Sector, in: Harvard Business Review, 65 (March-April), pp 118-126.

Jones, Thomas O. / W. Earl Sasser, Jr. (1995): Why Satisfied Customers Defect, in: Harvard Business Review, (November-December), pp 88-99.

Lovelock, Christopher H. (1988): Managing Services Marketing, Operations, and Human Resources. Englewood Cliffs, NJ: Prentice-Hall. 
Lytle, Richard S./ Peter W. Hom / Michael P. Mokwa (1997): SERVOR: An Organizational Measure of Service Orientation, in: Journal of Retailing (re-submit, Sept. 1997).

Nader, Buhler, Johnson (1996): Kundenzufriedenheit und Unternehmenserfolg: Eine kausalanalytische Betrachtung am Beispiel des Privatkreditgeschafts von Universalbanken, in: Bank Archiv, 44 (9), pp 702-710.

O’Connor, Stephen J. / Richard M. Shewchuk (1995): Service Quality Revisited: Striving for a New Orientation, in: Hospital \& Health Services Administration, 40 (4), pp 535-552.

Parasuraman, A./ Valarie Zeithaml / Leonard L. Berry (1985): A Conceptual Model of Service Quality and Its Implications for Future Research, in: Journal of Marketing, 49 (Fall), pp 41-50.

Parasuraman, A./ Valarie Zeithaml / Leonard L. Berry (1988): SERVQUAL: A Multiple-Item Scale for Measuring Consumer Perceptions of Service Quality, in: Journal of Retailing, 64 (Spring), pp 13-40.

Roach, Stephen S. (1991): Services Under Siege--The Restructuring Imperative, in: Harvard Business Review, (September-October), pp 82-91.

Schlesinger, Leonard A. / James L. Heskett (1991): The Service-Driven Service Company, in: Harvard Business Review, (September-October), pp 71-81.

Schmid, Daniel C. (1996): Kundenzufriedenheits-Management, in: Bank Archiv, 44 (3), pp 179-184.

Schneider, Benjamin / D. E. Bowen (1995): Winning the Service Game. Boston, MA: Harvard Business School Press.

Schneider, Benjamin / Arnon E. Reichers (1990): Climate and Culture: An Evolution of Constructs, in: Benjamin Schneider (Ed.): Organizational Climate and Culture. San Francisco: Jossey-Bass.

Schneider, Benjamin / Jill K. Wheeler / Jonathan F. Cox (1992): A Passion for Service: Using Content Analysis to Explicate Service Climate Themes, in: Journal of Applied Psychology, 77 (5), pp 705-716.

Sewell, Carl / Paul B. Brown (1992): Customers for Life: How to Turn That One-Time Buyer into a Lifetime Customer. New York: Doubleday.

Stalk, George / Jr., David K. Pecaut / Benjamin Burnett (1996): Breaking Compromises, Breakaway Growth, in: Harvard Business Review, (September-October), pp 131-139.

Treacy, Michael / Fred Wiersema (1993): Customer Intimacy and Other Value Disciplines, in: Harvard Business Review, (January-February), pp 84-95.

Zeithaml, Valarie A. / A. Parasuraman / Leonard L. Berry (1990): Delivering Quality Service: Balancing Customer Perceptions and Expectations. New York: The Free Press. 